\title{
Policy intervention and technical change in mature industry: The Swedish pulp and paper industry and the biorefinery
}

\author{
Kersti Karltorp ${ }^{1, *}$, Björn A Sandén ${ }^{1}$ \\ ${ }^{1}$ Chalmers University of Technology, Department of Energy and Environment, Gothenburg, Sweden \\ *Corresponding author. Phone:+46 317724907, E-mail: kersti.karltorp@chalmers.se
}

\begin{abstract}
Energy technologies based on biomass conversion are put forward as major means to curb climate change and enable a transition to a carbon neutral society. Many policies at international and national level are set up to support this transition. The pulp and paper industry is strongly linked to the conversion of biomass in Sweden and have a decisive role for the future of these technologies. This study aims to describe and explain the Swedish pulp and paper industry's reaction to policy with regard to the development of biorefineries. It turns out that firms are developing along two technological trajectories; 1) gasification for fuel production with a business model similar to the current one and 2) separation and refining for production of high value products, which requires a modified business model. Firms are also repositioning themselves within the regime and across regime borders. We conclude that the regime is in a phase of fragmentation. The policy implications from this analysis are that effective policy intervention needs to consider that multiple signals that are affecting the regime and policies should be designed depending on what degree of regime fragmentation that is desirable.
\end{abstract}

Keywords: Energy policy, Biorefinery, Pulp and paper industry, Multilevel perspective, Incumbent firm strategy

\section{Introduction}

A transition to a carbon neutral society will require extensive efforts to curb climate change. This involves large-scale changes in the energy system, switching from fossil to renewable energy sources. In Sweden increased use of biomass is considered as one step along this path, since the country has large biomass resources. Policies at international and national level, e.g. EU's directive on promotion of use of energy from renewable sources and the green certificates in Sweden, put forward energy technologies based on biomass conversion as major means to enable this transition. The pulp and paper industry in Sweden is strongly linked to the development of energy technologies based on biomass conversion, since the industry are in control of a large proportion of the biomass flow and have extensive knowledge of technologies based on biomass feedstock. Thus the industry can effectively hinder or induce the development of these technologies and consequently the transition that large-scale diffusion of these technologies could permit. Implementation of this type of technologies in the pulp and paper industry is often referred to as conversion of pulp and paper mills to biorefineries, i.e. a plant that efficiently use the incoming biomass to produce chemicals and energy simultaneously or instead of conventional fibers for paper products (definition inspired by [1]). Moreover, the pulp and paper industry is a large actor in the Swedish society, employing around 23,000 people in the country and contributing to $11 \%$ of Swedish exports [2]. Due to the strong link to biomass conversion and the size of the industry, it is an important actor for the development of biorefineries in Sweden. Policies' strong incentive for development of these technologies and the pulp and paper industries central role for biomass conversion make it important to understand the industry's reaction to policy. This study aims to describe and explain the Swedish pulp and paper industry's reaction to policy with regard to the development of biorefineries. In order to describe how the regime, that constitutes the Swedish pulp and paper industry, is reacting this article combines literature on transition and strategy. 


\section{Methodology}

This section describes how data was collected and the theoretical framework used for the analysis.

\subsection{Data collection}

For this study data was collected 2009-2010, through semi-structured interviews with representatives (often technical directors) from the Swedish pulp and paper industry. Other stakeholders, e.g. Universities and research companies, were also interviewed. The companies interviewed for this study represents more than $75 \%$ of the pulp and paper production in Sweden. The study is mainly focusing on the companies' operations in Sweden, even though it can be difficult to isolate international companies' strategies and actions to one country.

\subsection{Theoretical framework}

What policy that is viewed as effective in the steering of technical change processes depends on what model that is used to understand the system. A simple model could be that policy is seen as a signal going into the system urging the system to react. In contrast to this model, empirical evidence suggests that the adoption and wide diffusion of novel technologies tends to take many decades [3] and that incumbent firms are unwilling to make radical changes but tend to focus on incremental change along a trajectory within the prevailing technological paradigm [4, 5]. Nevertheless, over longer time frames the economy is characterised by the emergence, development and decline of different industries [6, 7]. Rip and Kemp [8] suggested a three layer model of technical change, further developed by Shot and Geels [9, 10] to explain the dynamics of such technological transitions. The intermediate layer, called the 'regime level', is constituted by a well-established socio-technical system that provides a function or a set of products. This includes the incumbent firms in an industry, consumers and other involved actors as well as technical infrastructures and production systems and the regulatory, normative and cognitive rules deciding what is allowed, desirable and sensible. At a micro level new technological options grow in 'niches'. Over time these may challenge the existing regime and form new systems. It is argued that such change is made possible by changes at a higher society wide macro level, the 'socio-technical landscape', which put pressure on the regime and destabilizes it and thereby opens windows of opportunities for niche technologies [9].

In the multi-level perspective (MLP) tradition it is recognised that regime change can take many pathways [10]. Additionally, as has been recognised before in the literature on economics of innovation [e.g. 7], incumbent actors may have critical roles also in radical change processes [10]. New biomass conversion technologies need to be linked up to biomass flows already governed by mature industries. This may indicate that biorefineries are more likely associated with a 'transformation path' [10], rather than more disruptive transition patterns. If such a transformation path is to be guided by policy, we believe it is crucial to develop more refined descriptions of regime dynamics. In the MLP literature 'the regime' tends to be treated at a highly aggregated level. To trace the emergence of regime fragmentation and transformation processes we see a need to decompose this aggregate. More specifically, we believe that much could be gained if the implications of the diversity among incumbent firms were studied more closely. To this end the literature on firm strategy can contribute.

According to Porter [11], a firm should strive to create a unique and valuable position. There are two strategies to achieve this. Either the firm should try to perform different activities 
compared to its rivals or it should perform the same activities as its rivals, but perform them differently. In addition, the strategy should protect the industry structure, rather than threaten it since this could result in decreased industry profitability. Thus from Porter's perspective incumbent firm gain the most by diversifying its activities, but only so much that they still reinforce the prevailing industry regime. Porter also stresses the importance of clusters for driving direction and pace of innovation [12]. Another perspective is offered by the resource based view, in which e.g. Grant [13] claims that a competitive position is best explained by the firm's resources and capabilities. Firms should identify its internal resources and skills and match these against the opportunities and risks created by its external environment. However, incumbent firms often find it difficult to adapt to changes at the landscape level if it requires strategies that are not aligned with its core capabilities, which then can become core rigidities [14]. Additionally, firms are not acting in accordance with some universal rationality. Instead, they are guided by mental models, which are used as a filter to simplify reality and enable decision making [15]. These models are based on successes and failures of previous actions, but are seldom explicit. Yet, these models are only valid as long as the variables and circumstances they are based on are not changed [15]. Thus changes at the landscape level could imply that a new mental model must be developed in order to make better decisions.

In combination these views on firm strategy suggest that if we want to understand regime response to multiple landscape pressures and new technological opportunities we need to take into account the relative positioning of firms in industries, geographical clusters, the firms' capabilities and their individual historical experiences of success and failure.

\section{A multilevel perspective on the Swedish pulp and paper industry}

This chapter describes the Swedish pulp and paper industry from a multilevel perspective, including the industry structure at a regime level, changes at a landscape level and finally technological developments at a niche level.

\subsection{Industry structure at regime level}

The companies within the Swedish pulp and paper industry have different characteristics and prerequisites for development and implementation of biorefinery options. From a technical perspective, the type of mill is important. Most mills are integrated mills, which mean that they have both pulp and paper production at the same site [16]. Integration of biorefinery options is of interest in pulp mills, which can be divided into two categories mainly mechanical, i.e. the raw material is grinded mechanically, or mainly chemical, i.e. the raw material is treated with chemicals and heat to degrade and dissolve the lignin from the cellulose and hemicelluloses [16]. Due to the large flow of by-products in chemical processes there are many opportunities for integration of biorefinery solutions in chemical pulp mills.

Within the industry, there are large variations in firm size and extent of vertical integration, ranging from firms operating one single mill, e.g. Domsjö Fabriker, to large multinational companies, e.g. Stora Enso. The diversity in the industry is illustrated in Fig. 1, in which the extent of vertical integration and difference in size are shown for six Swedish pulp and paper firms. 


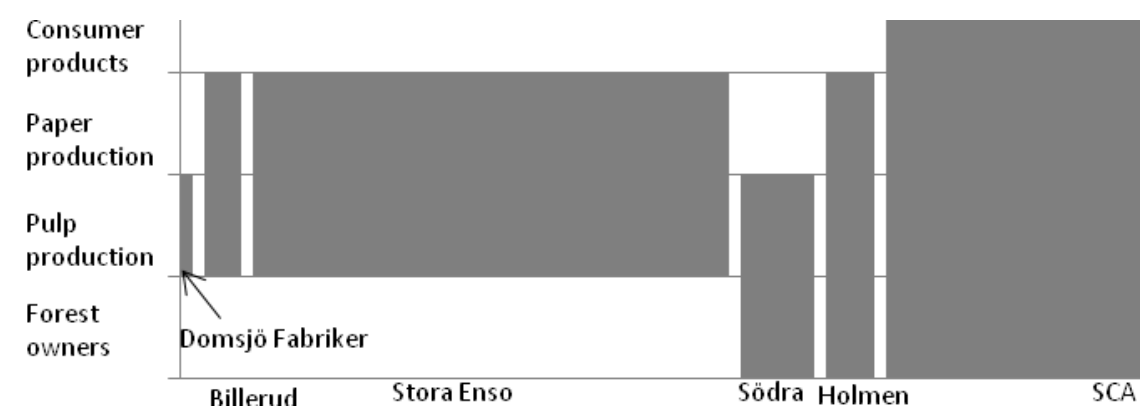

Fig. 1 The diversity in vertical integration and firm size for six Swedish pulp and paper firms. The value chain is characterised by four segment; forest ownership (ownership of 50\% or more of raw material requirements), pulp production, paper production and production of consumer products. The size is indicated by relating the number of employees to the size of the bar that represent each firm.

Firms' actions are also governed by the mental models. One example of two different mental models of company leaders could be seen when Domsjö Fabriker was created in 2000, as a result of a small group of people buying the pulp mill from the corporation MoDo. In contrast to the former owner the new owners were convinced that the unprofitable pulp mill could be transformed into a modern biorefinery [17].

\subsection{Landscape changes}

We can identify three main trends at the landscape level that are influencing the industry: changing patterns of demand for paper, economic and industrial development in South America and Asia and increased political attention to energy and environmental issues. While none of these have unambiguous effects, all of them create tension at the regime level.

During the last decades the printed media has experienced competition from electronic media, the industry has experienced decreasing demand, particularly for news print [18]. On the other hand, demand for personal care products is increasing as living standards are raised in many countries. The same applies for packaging products, probably as a result of the debate on climate change that has emphasised the importance of renewable materials [19].

The European market is the main market for most Swedish pulp and paper companies and Sweden's part of the supply has increased at the same modest pace as the European consumption [18]. The rapid economic growth in other parts of the world opens potential new markets. However, increased production capacity in South America and Asia reduces the possibility for European companies to take advantage of these emerging markets. Instead, these companies face competition from firms outside Europe with lower production and feedstock costs.

The debate on climate change and security of energy supply has resulted in raised prices on electricity and fuels, which has increased the production cost for the European pulp and paper industry. European mills have become more energy efficient, less fuel oil and other fossil fuels are used and the fraction of biomass in total fuel consumption has increased [20]. These trends are also valid for the Swedish pulp and paper industry, which produces more electricity with back-pressure power and deliver more heat to nearby communities [18]. 


\subsection{Technological developments at niche level}

The technological development of biorefineries has been going on for decades and can be divided into two main technological fields; 1) gasification and 2) separation and refining. In Sweden, the development of the gasification started in the 1970s with an emphasis on production of methanol, mainly through gasification of coal and peat, but biomass was also considered as a possible fuel [21]. As the focus shifted to ethanol produced by enzymatic hydrolysis in the 1980s, gasification was no longer prioritized. Despite this the competence about the technology lived on in the electricity sector [21]. In the mid 1990s to early 2000s the gasification technology re-emerged in three parallel tracks; biomass gasification for production of dimethyl ether (DME) or Fisher Tropsch (FT) diesel and finally gasification of black liquor to produce methanol [21]. The future development of both gasification and enzymatic hydrolysis for ethanol production is now dependent of successful pilot and demonstration plants. Some technologies have, however, reached a commercialisation state for example LignoBoost, which is a process for lignin extraction and an example of a separation technology. Södra is today working on a plant in commercial scale and research for future applications of lignin is going on in parallel [22].

\section{Regime response}

The result of changes at landscape level and technological niche developments can be seen in the regime, as the first signs of a fragmentation becomes visible. We identify restructuring along two different technological trajectories. We also observe repositioning within existing value chains and more radical repositioning, i.e. repositioning that transcends traditional industry boundaries.

\subsection{New technological trajectories}

Biorefinery concepts offer new business opportunities for an industry regime under pressure from landscape changes. However, while fuel production from the large biomass resource of the Swedish forests has been a primary target for Swedish Energy Authorities since the end of the 1970s, the Swedish pulp and paper industry has demonstrated little interest [21]. With the increased pressure over the last couple of years this is now slowly changing. While few companies have gone so far that they have actually started to implement biorefinery technologies many are now becoming engaged in research and investigations of options that can convert their mills into biorefineries. In different ways, the companies try to match the new technological options with their existing processes and business models. At this point we can distinguish two main technological trajectories.

\subsubsection{Gasification and fuel production}

The first trajectory is centred on gasification technologies. Biomass or black liquor can be used as raw material for this process. The product is syngas, which can be used for the production of a spectrum of refined products for example methanol, methane, DME, FT diesel and hydrogen. Companies that are interested in gasification of biomass or black liquor tend to focus on production of bio fuels rather than chemicals, which equally well could be produced. In most cases the companies are interested in gasifying low grade biomass in parallel to continued production of pulp or paper. The business model behind this strategy seems to rely on the possibility to sell large volume of fuel, in a similar way as pulp or paper are sold today. However, additional biomass will be needed for implementation of these technologies.

Stora Enso motivates its preference for biomass gasification technology with the argument that it is flexible in the choice of end product and in the choice of raw material, thus different 
raw materials could be used at different geographical locations [19]. The preference for transportation fuels is driven by the competences their partner, Neste Oil, has in this field and the belief that the production of fuels can contribute more to prevent climate change than production of materials [19]. The arguments for this option reflect the present business model's focus on efficient production of bulk products. While implying major investments in new technology, the change in business model is minor and the core business of producing pulp and paper is not questioned.

\subsubsection{Separation and refining to high value products}

The processes employed in the second trajectory are typically enzymatic processes, hydrolysis and fermentation. Compared to gasification technology the choice of process is linked more directly to a specific product. Companies in this trajectory have a broader perspective on the kind of products they could produce in the future; chemicals, materials or possibly fuels. The business model linked to these products focuses on the possibility to sell small quantities of these products at a high price. One key argument for this strategy is to use the full potential of the fiber in biomass. The industry has traditionally done a lot of research on cellulose fiber. Consequently, utilising knowledge about cellulose fibers for production of materials and chemicals relates to one of the industry's core competences.

Södra with their implementation of the LignoBoost technology and Domsjö Fabriker's production of specialty cellulose for production of viscose clothes are both examples of development along this trajectory. These firms have in common that they operate (nonintegrated) chemical pulp mills. Södra has investigated many different technological options, driven by the will to extend capacity at its mills and the need to find new energy carries to increase the export of energy from the mills [22]. The outspoken argument for production of specialty cellulose, for the clothes market, at Domsjö is that cotton is claimed to be less environmentally friendly due to the large quantities of chemicals and water that is used for its production. Hence, materials produced from forest products, like viscose, could offer a more environmentally friendly solution [23]. Since the amount of raw material needed for realization of options along this trajectory could be small, the original process could be affected to a minor extent and additional biomass is not necessarily needed. In this way companies can create more value from the same input. There are, however, technological options along this trajectory that would include the entire raw material flow, such as production of ethanol from cellulose, but none of the interviewed companies show any signs of interest in restructuring its processes entirely for this process.

\subsection{Repositioning within a regime and across regime borders}

Vertical integration is a strategy that could be used to achieve a competitive position within an industry. For SCA, which has a high degree of vertical integration (see Fig. 1), it seems to have been a successful choice to keep its forests and at the same time pursue a vertical integration towards personal care products [24]. Billerud is another example of a firm that shows a tendency to extend its vertical integration as they have initiated a co-operation with a well-pap packaging company, which contributes to increase Billerud's access to the market for transportation of fruit and vegetables [25].

One example of a more radical repositioning, i.e. repositioning beyond current value chains or across regime borders, is the joint venture between Stora Enso and Neste Oil for development of gasification technology and transport fuels [19]. Smaller firms seek collaboration in local clusters, e.g. in the area around Örnsköldsvik a cluster involving research company, 
universities, municipalities and the pulp producing company Domsjö Fabriker are working together to develop 'the biorefinery of the future'. In southern Sweden, Södra has been operating closely with the research organisation Innventia and Chalmers University of Technology. Within this cluster there is a shared belief in the development of high value products that can be produced in parallel to the existing pulp process. The repositioning between regimes indicates that a radical form of regime fragmentation involving several industry regimes may wait around the corner. The growing use of biomass for energy has made utility firms interested in biomass as a source of energy. The development of different types of biorefinery concepts for production of chemicals or fuels also attracts the chemical industry, the oil and gas industry and the car industry.

\section{Conclusions}

Political attention to energy and environmental issues has resulted in policies aiming at increased implementation of biorefinery concepts. However, this is not the only signal urging the industry to react. The Swedish pulp and paper industry regime is affected by several landscape changes and technological niche developments. Furthermore within the regime the firms have different prerequisites to react to policy and other external signals. The industry's reaction is characterised by technological development along two technological trajectories and a third trajectory of repositioning (partially overlapping the technological trajectories) within the regime and across regime borders, see Fig. 2. This can be regarded as a phase of fragmentation of the Swedish pulp and paper industry regime, but it is by no means clear where this regime fragmentation will end.

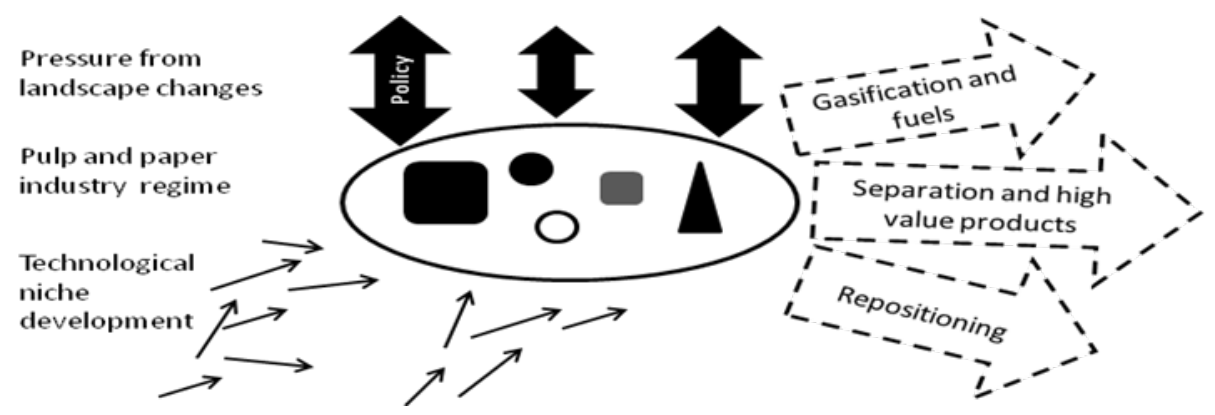

Fig. 2 The Swedish pulp and paper industry is affected by pressure from landscape changes, including policies, and technological niche developments. Furthermore within the regime the firms have different prerequisites for their reactions. The Swedish pulp and paper industry regime is restructuring itself along several trajectories initiating a phase of fragmentation.

In this context, policy makers need to consider how much fragmentation that is desirable. Strong policies will guide the industries towards a more uniform response, which could be attractive for achieving a rapid diffusion of novel technologies. A less forceful policy might encourage several trajectories to be followed in parallel, which could be desirable if policy makers have doubt about which technologies to diffuse and therefore would like several technologies to be developed and diffused.

\section{References}

[1] Ö. Larsson and B. Ståhl, More refined products - Wood based biorefineries increase the prices per kilo on wood (in Swedish), Vinnova, 2009.

[2] Pappers - Swedish Paper Workers Union, 2010, accessed 2010-08-26 at www.pappers.se. 
[3] A. Grübler, Time for a change: On the patterns of diffusion of innovation, Daedalus 125 (3), 1996, pp 19-42.

[4] R.R. Nelson and S.G. Winter, An evolutionary theory of economic change, Belknap Press of Harward University Press, 1982.

[5] G. Dosi, Technical paradigms and technological trajectories, Research Policy 11, 1982, pp 147-162.

[6] C. Freeman and F. Loucã, As Time Goes By: From the Industrial Revolutions to the Information Revolution, Oxford University Press, 2002.

[7] F. Malerba and L. Orsenigo, The dynamics and evolution of industries, Industrial and Corporate change 5(1), 1996, pp 51-87.

[8] A. Rip and R. Kemp, Technological Change in Human Choice and Climate Change, S. Rayner and E.L. Malone Editors, Battelle Press, 1998, pp 327-399.

[9] F.W. Geels, Technological transitions as evolutionary reconfigurations processes: a multi-level perspective and a case-study, Research Policy 31, 2002, pp1257-1274.

[10]F.W. Geels and J. Schot, Typology of sociotechnical transitions pathways, Research Policy 36(3), 2007, pp 399-417.

[11]M.E. Porter, What is strategy, Harvard Business Review November-December, 1996, pp 61-78.

[12]M.E. Porter, Clusters and the new economics of competition, Harvard Business Review November-December, 1998, pp 77-90.

[13]R.M. Grant, The Resource-Based Theory of Competitive Advantage: Implications for Strategy Formulation, California management Review 33, 1991, pp 114-135.

[14]D. Leonard-Barton, Core Capabilities and Core rigidities: A Paradox in Managing New Product Development, Strategic Management Journal13, 1992, pp 111-125.

[15]R. Foster and S. Kaplan, Creative Destruction - Why companies that are built to last underpreform the market and how to successfully transform them, Doubleday, 2001.

[16]G.A. Smook, Handbook for pulp and paper technologists, Angus Wilde Publications Inc, 2002.

[17]M. Norlin, Interview with Director at the board at Domsjö Fabriker, 2010.

[18] Swedish Forest Industries, Facts and Figures 2009, 2009 (electronic format can be found at http://www.skogsindustrierna.org).

[19]A. Jääskeläinen, Interview with SVP Biorefining and Bioenergy at Stora Enso, 2009.

[20]CEPI, Key Statistics 2009 - European Pulp and Paper Industry, 2010.

[21] B. A. Sandén and K. M. Jonasson, Variety Creation, Growth and Selection Dynamics in the Early Phases of a Technological Transition -The Development of Alternative Transport Fuels in Sweden 1974-2004, Chalmers University of Technology, 2005.

[22]A. Andersson, Interview with Energy Coordinator at Södra Cell, 2009.

[23]P. Blomqvist, Interview with Manager of DomInnova at Domsjö Fabriker, 2010.

[24]A. Andersson, Interview with Director Technical Development at SCA Forest Products, 2010.

[25] M. Wikström, Interview with Technical Director at Billerud AB, 2009. 